\title{
Structural variations in actins
}

\author{
A study of the immunological reactivity of the $\mathrm{N}$-terminal region
}

\author{
Claude ROUSTAN, ${ }^{*} \S$ Yves BENYAMIN, $\dagger$ Mireille BOYER* and Jean-Claude CAVADORE $\ddagger$ \\ *LP 8402 Centre de Recherches de Biochimie Macromoleculaire, †Laboratoire de Biochimie et Ecologie des Invertebrés Marins \\ EPHE, and ¥U-249 I.N.S.E.R.M., B.P. 5051, 34033 Montpellier Cedex, France
}

\begin{abstract}
The antigenicity of the $N$-terminal region of skeletal-muscle actin was analysed. Two epitopes, corresponding to the 1-7 and 18-28 sequences, were determined. The antibodies specific for the first epitope discriminate skeletal-muscle actin from cardiac-muscle and smooth-muscle actins. The antibodies specific for the second epitope interact with all the actins tested, ranging from invertebrate to higher-vertebrate actins.
\end{abstract}

\section{INTRODUCTION}

In the last 10 years the amino acid sequences of different actin isoforms have been determined (Collins \& Elzinga, 1975; Vandekerckhove et al., 1983). In higher vertebrates six major actin isoforms are expressed (Vandekerckhove \& Weber, 1979; Vandekerckhove et al., 1983), two sarcomeric (cardiac-muscle and skeletalmuscle), two smooth-muscle (vascular and non-vascular) and two cytoplasmic actins. These actins show a high degree of homology in their primary structure except in the $N$-terminal part (Vandekerckhove \& Weber, 1984). Furthermore, actins from invertebrates and some ancestral vertebrates do not display more than a $6 \%$ variation in amino acid sequences (Vandekerckhove \& Weber, 1984). In all cases the variable $N$-terminal sequence $(1-17)$ is characterized by a cluster of negative charges (three or four consecutive dicarboxylic amino acid residues) (Vandekerckhove \& Weber, 1984). Thus antigenic probes directed at this major hydrophilic locus of mutation could be important tools for discriminating isoforms of actin and studying their distribution in cells and tissues.

In a previous paper (Roustan et al., 1985a) we reported the $N$-terminal specificity of antisera induced by skeletal-muscle filamentous actin. In the present paper we focus on an analysis of the antigenic reactivity of this particular sequence. We describe the presence of two antigenic epitopes. One antibody population is specific for skeletal-muscle actin, and the second is not specific at all. Overall, these results show that polyclonal antibodies, elicited by skeletal-muscle filamentous actin, can be fractionated to allow recognition of specific epitopes.

\section{MATERIALS AND METHODS}

\section{Actin and its chemically modified derivatives}

Rabbit skeletal-muscle, bovine cardiac-muscle, chicken gizzard-muscle, dogfish epaxial-muscle and scallop adductor-muscle actins were obtained as described by Spudich \& Watt (1971). Bovine aortic-muscle actin was obtained as previously described by Cavadore et al. (1985). Trinitrophenylation (3 mol of residues $/ \mathrm{mol}$ of actin) of F-actin was carried out as previously described (Benyamin et al., 1983). S-Carboxymethylated actin
(Benyamin et al., 1979) was coupled to Sepharose 4B by the CNBr procedure (Bottomley \& Trayer, 1975). F-actin was coupled to Sepharose $4 \mathrm{~B}$ by the $\mathrm{CNBr}$ procedure after glutaraldehyde treatment (Herman \& Pollard, 1979).

\section{Actin cleavage}

Actin was proteolysed by Staphylococcus aureus $\mathrm{V}_{\mathbf{8}}$ proteinase (Roustan et al., 1985a), trypsin (Jacobson \& Rosenbusch, 1976) and thrombin (Muszbek \& Laki, 1974). The $N$-terminal thrombic peptides (1-28 fragment) were isolated by h.p.l.c. Thrombic digests were fractionated on a $\mu$ Bondapak $\mathrm{C}_{18}$ column $(7.8 \mathrm{~mm} \times 300 \mathrm{~mm})$ with a $0-60 \%(\mathrm{v} / \mathrm{v})$ acetonitrile gradient in $0.01 \%(\mathrm{v} / \mathrm{v})$ trifluoroacetic acid. The eluate was monitored at $230 \mathrm{~nm}$. The amino acid composition of each peak was determined after acid hydrolysis, and compared with the calculated amino acid composition of the 1-28 peptide for identification. The isolated thrombic peptides from skeletal-muscle and aortic-muscle actins (Table 1) were coupled by glutaraldehyde treatment to haemocyanin, which acted as a carrier protein (Bulinski et al., 1983). All the small tryptic peptides, including the 1-62 sequence, were cleared from the actin core (Jacobson \& Rosenbusch, 1976) by acidic precipitation, and coupled to Sepharose 4B.

\section{Antibodies}

Antibodies to rabbit skeletal-muscle trinitrophenylated F-actin were obtained as described by Roustan et al. (1985a). Anti-(rabbit IgG) antibodies labelled with peroxidase or alkaline phosphatase were from Biosys (Compiegne, France). Antibody populations were purified by affinity chromatography (Andersson et al., 1978).

\section{Analytical methods}

Protein concentrations were determined by using the absorption coefficient determined by Rich \& Estes (1976) and Andersson et al. (1979). Sodium dodecyl sulphate $(0.1 \%) /$ polyacrylamide-slab-gel electrophoreses were run in accordance with the procedure of Laemmli (1970). Proteins and peptides were transferred to nitrocellulose as described by Roustan et al. (1982). The enzyme-linked immunosorbent assay technique was used to monitor the interaction between actins and antibody populations. 
Table 1. Comparative amino acid compositions of the 1-28 peptides obtained by thrombic proteolysis of aorticmuscle and skeletal-muscle actins

The calculated values are based on the known 1-28 sequences of aortic-muscle actin and skeletal-muscle actin.

\begin{tabular}{|c|c|c|c|c|}
\hline \multirow{3}{*}{$\begin{array}{c}\text { Amino } \\
\text { acid }\end{array}$} & \multicolumn{4}{|c|}{ Composition ( $\mathrm{mol}$ of residue $/ \mathrm{mol}$ of fragment) } \\
\hline & \multicolumn{2}{|c|}{ Aortic actin } & \multicolumn{2}{|c|}{ Skeletal-muscle actin } \\
\hline & Found & Calculated & Found & Calculated \\
\hline Asx & 5.0 & 5 & 5.6 & 6 \\
\hline Thr & 0.9 & 1 & 1.6 & 2 \\
\hline Ser & 1.9 & 2 & 0.7 & 1 \\
\hline Glx & 3.1 & 3 & 2.0 & 2 \\
\hline Gly & 4.1 & 4 & 3.6 & 4 \\
\hline Ala & 3.9 & 4 & 3.7 & 4 \\
\hline Val & 0.9 & 1 & 1.8 & 2 \\
\hline Met & 0.0 & 0 & 0.0 & 0 \\
\hline Ile & 0.0 & 0 & 0.0 & 0 \\
\hline Leu & 2.0 & 2 & 1.7 & 2 \\
\hline Tyr & 0.0 & 0 & 0.0 & 0 \\
\hline Phe & 0.9 & 1 & 1.3 & 1 \\
\hline His & 0.0 & 0 & 0.0 & 0 \\
\hline Lys & 1.2 & 1 & 0.8 & 1 \\
\hline Arg & 1.3 & 1 & 0.9 & 1 \\
\hline
\end{tabular}

Actins diluted to $200 \mu \mathrm{g} / \mathrm{ml}$ in $0.5 \mathrm{M}$-sodium bicarbonate buffer, pH 9.0, were coated in 96-well U-bottom micro-titre plates. After overnight incubation at $4{ }^{\circ} \mathrm{C}$, the plates were washed and $2 \%(\mathrm{w} / \mathrm{v})$ bovine serum albumin was added in order to saturate the free binding sites. After washing with PBS/Tween buffer [0.14 M- NaCl/0.01 Msodium phosphate buffer, $\mathrm{pH} 7.4$, containing $0.05 \%(\mathrm{v} / \mathrm{v})$ Tween 20], the plates were incubated with dilutions of the immune serum or purified antibodies for $12 \mathrm{~h}$ at $4^{\circ} \mathrm{C}$, after which the wells were washed five times with PBS/ Tween buffer containing $150 \mathrm{~mm}-\mathrm{KCl}$. Goat (anti-rabbit IgG) antibodies conjugated with alkaline phosphatase $(1 / 1000)$ was added and the mixture incubated for $2 \mathrm{~h}$ at room temperature. After a washing, a solution of $p$-nitrophenyl phosphate was added to the wells and the mixture incubated for $30 \mathrm{~min}$ at room temperature. The resulting absorbance at $405 \mathrm{~nm}$ was read automatically.

\section{Location of possible antigenic determinants}

This was done as described by Hopp \& Woods (1981). These authors show that the sequential epitopes are found in regions that are highly exposed to solvent, near the point of maximum hydrophilicity. The method is based on a calculation of the average hydrophilicity of the hexapeptides 1-6, 2-7 etc. along the amino acid sequence. Calculations were performed on a Mackintosh computer.

\section{RESULTS}

In a previous paper (Roustan et al., 1985a) we showed that antiserum induced by chemically modified filamentous actin is specific for the $1-62$ sequence of rabbit skeletal-muscle actin. We now demonstrate here that this antiserum does not react with the large fragments derived

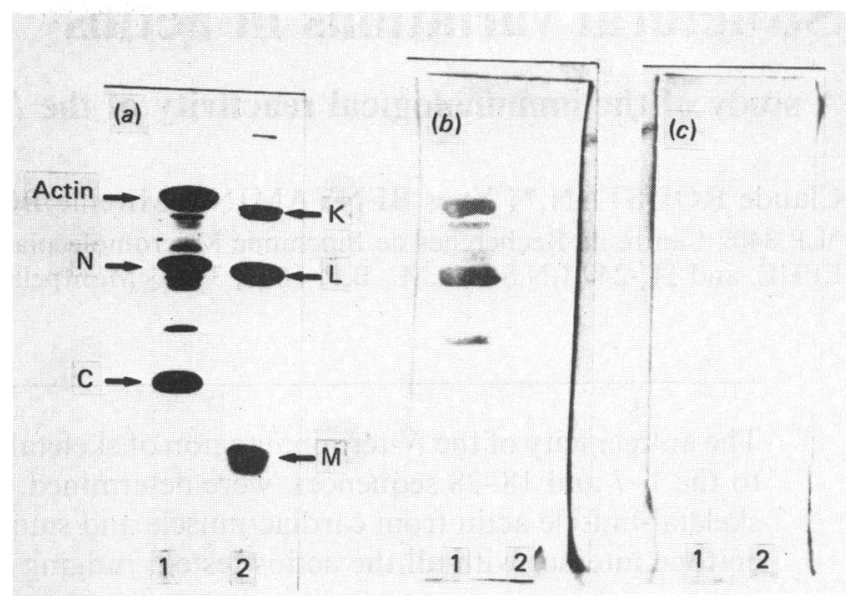

Fig. 1. Antigenic reactivity of electrophoretic blotting from $S$. aureus $V_{8}$ proteinase (1) and thrombin (2) actin digests

(a) shows the Coomassie Blue-stained polyacrylamide gel after electrophoresis. The electrophoretic replicates were revealed with anti-(trinitrophenylated F-actin) serum (b) and with the non-retained fraction of the same antiserum after loading on an insolubilized F-actin column (c). For experimental details see the text. $\mathrm{K}, \mathrm{L}$ and $\mathrm{M}$ represent the peptides obtained by thrombic digestion in accordance with the technique of Muszbek \& Laki (1974). C and N represent the $N$-terminal and $C$-terminal peptides of actin.

from a thrombic cleavage of actin (Fig. 1). In particular, the overlapping $K$ fragment (sequence 40-375) was not recognized.

Moreover, antibodies directed to the 1-39 sequence, which cross-reacted with the unfolded form of actin, as shown in the immunoblots (Fig. 1), had a strong reactivity with the native filamentous form. When this serum was passed through an insolubilized F-actin column (obtained by immobilization of skeletal actin on Sepharose CL6B by using the CNBr coupling procedure), all the anti-actin antibodies were retained (Fig. 1). We conclude that the antigenic sites of the 1-39 sequence are accessible in native filamentous actin.

The crude antiserum was tested against the different purified muscle actins, with nitrocellulose-based replicates from warm-blooded vertebrates (rabbit skeletal-muscle, bovine cardiac-muscle, bovine aortic-muscle and chicken gizzard-muscle actins), ancestral vertebrate (dogfish epaxial-muscle actin) and invertebrate (scallop adductormuscle actin). All these actins were recognized by the antiserum (Fig. 2). In addition, the thrombic peptide (sequence 1-28) from skeletal-muscle and aortic-muscle actins reacted with the antiserum, as determined by the enzyme-linked immunosorbent assay technique (Fig. $3 a$ ). The serum was fractionated on a column of insolubilized tryptic peptides mapping the 1-62 sequence of skeletalmuscle actin. The flow-through fraction was further purified on an insolubilized unfolded actin column and the adsorbed antibodies were eluted (fraction II) by $20 \mathrm{~mm}$-sodium phosphate containing $10 \%$ (v/v) dioxan adjusted to $\mathrm{pH} 12$ and immediately neutralized. The adsorbed fraction (fraction I) on the insolubilized tryptic-peptide column was.also eluted by 20 mM-sodium phosphate containing $10 \%$ (v/v) dioxan adjusted to pH 12. These two adsorbed antibody populations were 

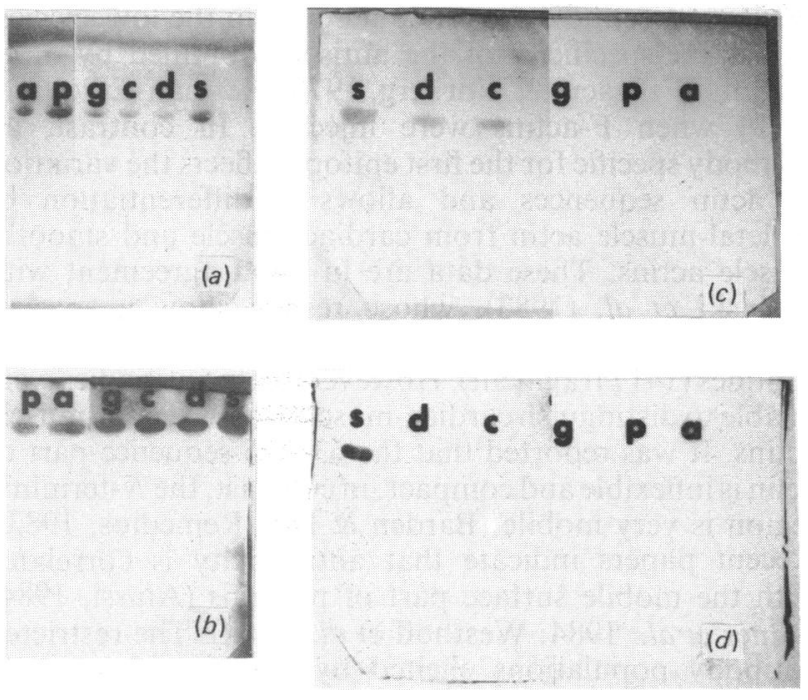

Fig. 2. Antigenic reactivity of various actins with antiactin serum or purified antibody populations

Actins were from rabbit skeletal muscle (s), bovine aortic muscle (a), chicken gizzard (g), dogfish epaxial muscle (d) and scallop adductor muscle (p). The electrophoretic replicates were tested with $(a)$ crude antiserum $(1 / 10$ dilution), (b) purified antibody fraction II $(0.2 \mathrm{mg} / \mathrm{ml}),(c)$ purified antibody fraction $I(0.2 \mathrm{mg} / \mathrm{ml})$ and $(d)$ purified antibody fraction I $(0.04 \mathrm{mg} / \mathrm{ml})$. For experimental details see the text. tested by two different techniques, immunoblot and enzyme-linked immunosorbent assay. The results are presented in Figs. 2 and 3. The antibody populations that were not retained on the insolubilized tryptic-peptide column reacted with all the actins tested and therefore did not show any marked specificity, similarly to the starting antiserum.

In contrast, the second population of purified antibodies enabled us to discriminate between the actin isoforms. In particular, the antibodies reacted well with skeletal-muscle actin, but to a lesser extent with cardiac-muscle and dogfish epaxial-muscle actins. The latter reactions disappeared when lower concentrations of antibodies were used (dilution of $1 / 50 ;$ Fig. $2 d$ ). The other actins did not react at all. These results are in good agreement with those obtained by enzyme-linked immunosorbent assay (Figs. $3 b$ and $3 c$ ).

\section{DISCUSSION}

In a previous paper we demonstrated differential reactivity among actins from various species, by using an actin antiserum with high specificity (Benyamin et al., 1979). However, more-specific antibodies were needed to probe differences between actins. For this reason we have attempted to produce antisera directed against the most variable part of actin, i.e. the $N$-terminal region.

Several of the antisera produced interacted with the $N$-terminal sequence of actin (Roustan et al., 1985a,b; Boyer et al., 1985). One of them, induced by an injection
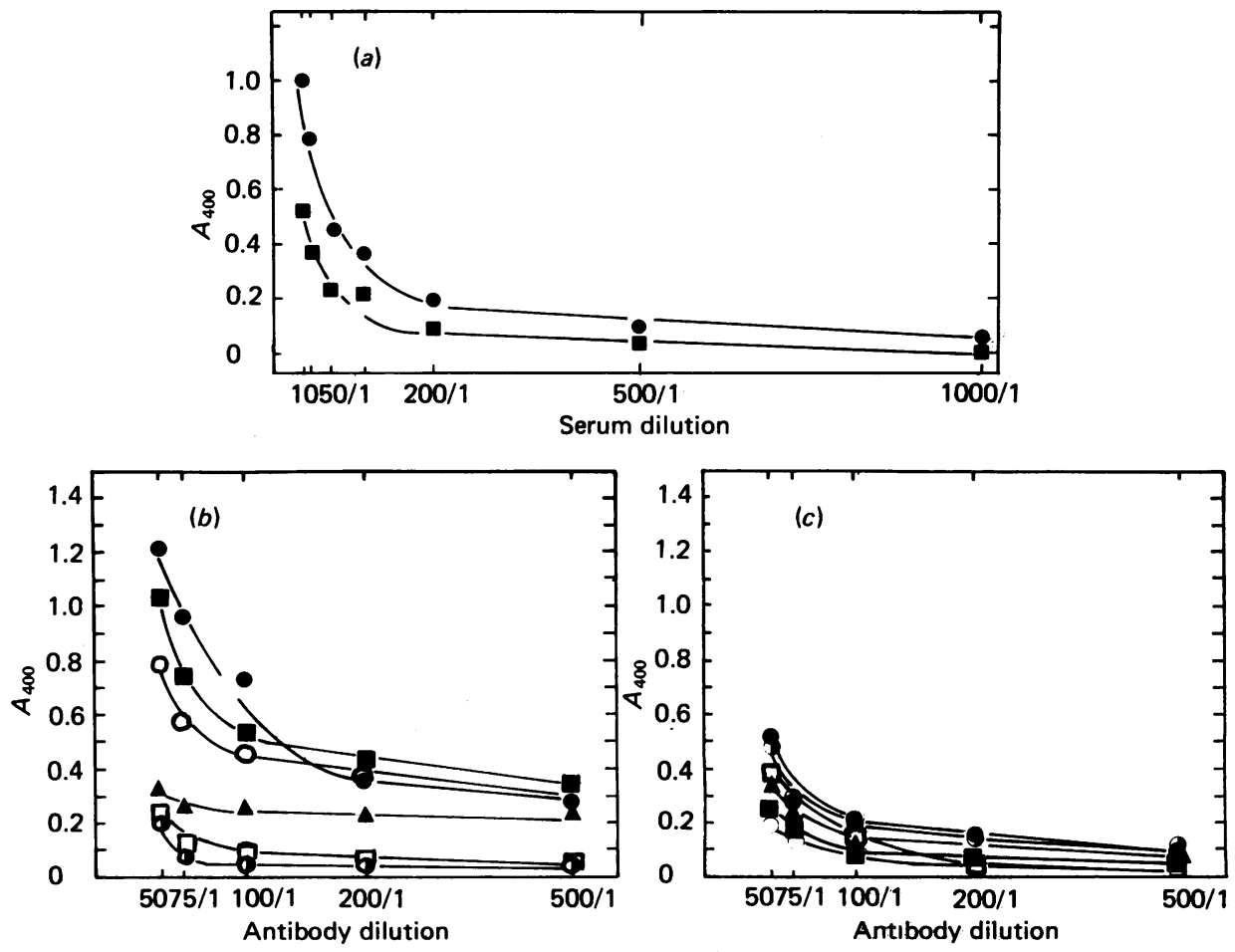

Fig. 3. Immunoreactivity of various actins or actin peptides revealed by enzyme-linked immunosorbent assay

(a) shows the reaction of the actin 1-28 peptides from aortic $(\square)$ and skeletal-muscle actin ( $O$ ) with the antiserum. These peptides were coupled to haemocyanin, by glutaraldehyde treatment, before being coated $(0.2 \mathrm{mg} / \mathrm{ml})$ on the micro-titre plates. $(b)$ and (c) show the immunoreactivity of various actins with purified antibody fractions I and II respectively. The actins coated were from rabbit skeletal muscle $(O)$, bovine cardiac muscle $(O)$, bovine aortic muscle $(\square)$, chicken gizzard muscle $(\Delta)$, dogfish epaxial muscle $(\square)$ and scallop adductor muscle $(\boldsymbol{O})$. For experimental details see the text. 


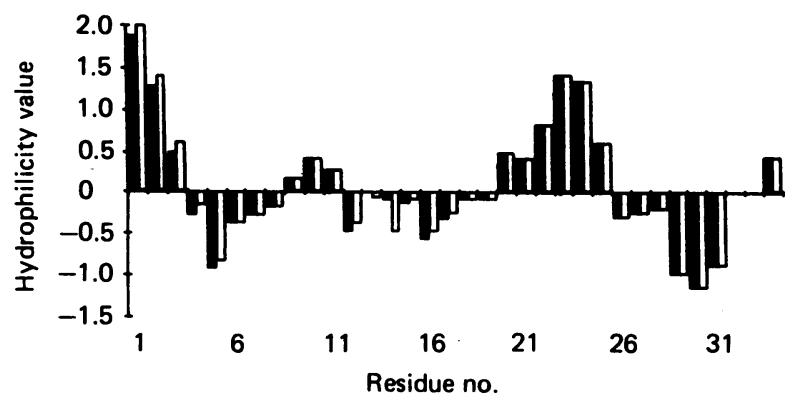

Muscle

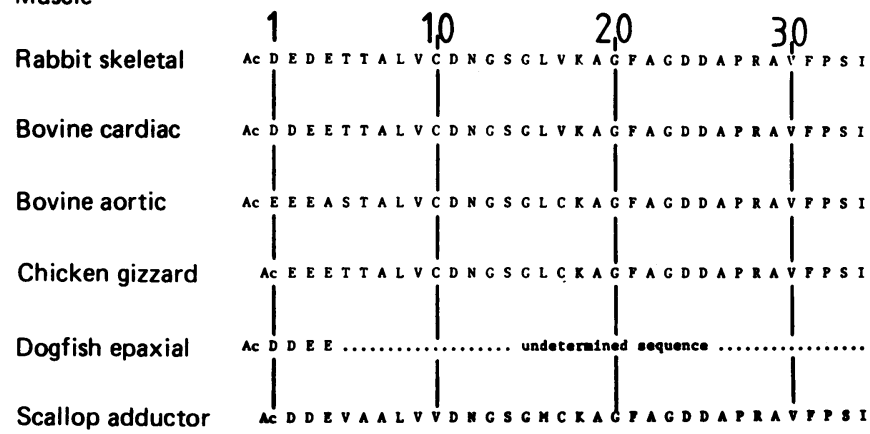

Fig. 4. Average hydrophilicity value of each hexapeptide plotted versus its position in the sequence

The hydrophilicity pattern of skeletal-muscle actin $(\square)$ and aortic-muscle actin ( $\square$ ) and the sequence of the various actins reported in Vandekerckhove \& Weber (1984) are shown at the top and the bottom of the Figure respectively.

of filamentous trinitrophenylated actin, appeared to be specific for the 1-39 sequence of skeletal-muscle actin. Consequently, we here examined the potential antigenicity of the variable region of actin. The prediction method developed by Hopp \& Woods (1981) revealed the presence of two marked hydrophilic regions, which could contain the antigenic epitopes of the $N$-terminal part. The first corresponded to the 1-7 fragment and the second one to the 23-29 region (Fig. 4). Furthermore, variation in the hydrophilicity between actins essentially occurred in the 1-6 sequence, and the maximal hydrophilicity was observed with aortic-muscle actin (Fig. 4). In contrast, we observed no variation in the hydrophilicity pattern between skeletal-muscle and cardiac-muscle actins, where sequence changes are decreased to one inversion. The present investigation shows that one antibody population, which is tissue- and species-specific, corresponds to at least a part of the variable 1-17 sequence (Vandekerckhove et al., 1983; Vandekerckhove \& Weber, 1984). The discrimination observed between skeletal-muscle and cardiac-muscle actins indicated an epitope location in the 1-7 region. The second antibody population, which reacted with all the actins tested, is thus related with the constant region (i.e. 18-28 sequence). This assertion is also supported by the observed interaction between the antiserum and the aortic-muscle thrombic 1-28 peptide.

In addition, the presence of other epitopes in the 29-38 region seems improbable on the basis of the hydrophobicity of this region. The localization of the first epitope in the variable 1-7 region and the second epitope in the constant $18-28$ region fits very well with the predicted model.

The presence of an antibody specific for the constant sequence (second epitope) could explain the low speciesand tissue-specificity of the antisera obtained by other authors (Fragaeus \& Norberg, 1978; Herman \& Pollard, 1979) when F-actins were injected. In contrast, an antibody specific for the first epitope reflects the variation of actin sequences and allows a differentiation of skeletal-muscle actin from cardiac-muscle and smoothmuscle actins. These data are in good agreement with Bulinski et al. (1983), whose results show a speciesspecificity in the antiserum elicited by $N$-terminal tryptic peptides (1-17 fragment). However, these antibodies were unable to distinguish cardiac-muscle from skeletal-muscle actins. It was reported that the 63-375 sequence part of actin is inflexible and compact; in contrast, the $N$-terminal region is very mobile (Barden \& Dos Remedios, 1983). Recent papers indicate that antigenicity is correlated with the mobile surface part of proteins (Atassi, 1984; Tainer et al., 1984; Westhoff et al., 1984). The restricted antibody populations elicited by filamentous trinitrophenylated actin results from the decreased number of mobile segments in actin. In this specific case the fractionation of a polyclonal antibody obviates the necessity to use monoclonal techniques in order to obtain specific probes for the $N$-terminal sequence of actin. In conclusion, our antibody population directed against the first epitope should be able to probe differential isoform expression during myogenesis or to analyse differential expression in pathological disorders.

\section{REFERENCES}

Andersson, K. K., Benyamin, Y., Douzou, P. \& Balny, C. (1978) J. Immunol. Methods 23, 17-21

Andersson, K. K., Benyamin, Y., Douzou, P. \& Balny, C. (1979) J. Immunol. Methods 25, 375-381

Atassi, M. Z. (1984) Eur. J. Biochem. 145, 1-20

Barden, J. A. \& Dos Remedios, C. G. (1983) in Actin: Structure and Function in Muscle and Non-Muscle Cells (Dos Remedios, C. G. \& Barden, J. A., eds.), pp. 53-62, Academic Press, New York

Benyamin, Y., Roger, M., Gabrion, J., Robin, Y. \& Thoai, N. V. (1979) FEBS Lett. 102, 69-74

Benyamin, Y., Roustan, C. \& Boyer, M. (1983) FEBS Lett. 160, 41-45

Bottomley, R. C. \& Trayer, I. P. (1975) Bichem. J. 149, 365-379

Boyer, M., Roustan, C. \& Benyamin, Y. (1985) Biosci. Rep. 5, $39-46$

Bulinski, J. C., Kumar, S., Titani, K. \& Hauschka, S. D. (1983) Proc. Natl. Acad. Sci. U.S.A. 80, 1506-1510

Cavadore, J. C., Axelrud-Cavadore, C., Berta, P., Harricane, M. C. \& Haiech, J. (1985) Biochem. J. 218, 433-441

Collins, J. \& Elzinga, M. (1975) J. Biol. Chem. 250, 5915-5920

Fragaeus, A. \& Norberg, R. (1978) Curr. Top. Microbiol. Immunol. 82, 1-13

Herman, I. M. \& Pollard, T. D. (1979) J. Cell Biol. 80, 509-529

Hopp, T. P. \& Woods, K. R. (1981) Proc. Natl. Acad. Sci. U.S.A. 78, 3824-3828

Jacobson, G. R. \& Rosenbusch, J. P. (1976) Proc. Natl. Acad. Sci. U.S.A. 73, 2742-2746

Laemmli, U. K. (1970) Nature (London) 227, 680-685

Muszbek, L. \& Laki, K. (1974) Proc. Natl. Acad. Sci. U.S.A. 71, 2208-2211

Rich, S. A. \& Estes, J. E. (1976) J. Mol. Biol. 104, 777-792

Roustan, C., Boyer, M., Fattoum, A., Jeanneau, R., Benyamin, Y., Roger, M. \& Pradel, L. A. (1982) Eur. J. Biochem. 129, 149-155

Roustan, C., Benyamin, Y., Boyer, M., Bertrand, R., Audemerd, E. \& Jauregui-Adell, J. (1985a) FEBS Lett. 181, 119-123 
Roustan, C., Benyamin, Y. \& Boyer, M. (1985b) J. Muscle Res. Cell. Motil. 6, 79

Spudich, J. A. \& Watt, S. (1971) J. Biol. Chem. 246, 48664871

Tainer, J. A., Getzoff, E. D., Alexander, H., Houghton, R. A., Olson, A. J., Lerner, R. A. \& Henrickson, W. A. (1984) Nature (London) 312, 127-134

Vandekerckhove, J. \& Weber, K. (1979) Differentiation 14, 123-133

Received' 22 May 1985/5 August 1985; accepted 9 September 1985
Vandekerckhove, J. \& Weber, K. (1984) J. Mol. Biol. 179, 391-413

Vandekerckhove, J., De Couet, H. G. \& Weber, K. (1983) in Actin: Structure and Function in Muscle and Non-Muscle Cells (Dos Remedios, C. \& Barden, J. A., eds.), pp. 241-248, Academic Press, New York

Westhoff, E., Ailsuch, D., Moras, D., Bloomer, A. C., Mondragon, A., Klug, A. \& Van Regenmortel, M. H. V. (1984) Nature (London) 311, 123-126 